This is the author's pre-print manuscript as submitted for refereeing and publication. The penultimate, refereed, publisher-formatted PDF may be available through the journal web site or, your college and university library.

\title{
The mathematical modeling of structural engineers
}

Julie Gainsburg

\section{Manuscript Citation}

The following ( APA) citation may be used to reference this manuscript:

Gainsburg, J. (2006). The mathematical modeling of structural engineers. Retrieved from http://scholarworks.csun.edu

\section{Published Version Information}

Citation: Gainsburg, J., (2006). The mathematical modeling of structural engineers. Mathematical Thinking and Learning, 8:1, 3-36.

Copyright: Copyright $@$ Taylor \& Francis Group, LLC

Digital Object Identifier (DOI): 10.1207/s15327833mt|0801_2

This item was retrieved from CSUN ScholarWorks, the open-access, institutional repository of California State University, Northridge. http://scholarworks.csun.edu 
Running head: MODELING OF ENGINEERS

The Mathematical Modeling of Structural Engineers

Julie Gainsburg

California State University, Northridge

This study was made possible by a Stanford Graduate Fellowship. I am indebted to James Greeno and Diane Bailey, who were invaluable advisors, and to the engineers who volunteered to participate. I also thank Janet Bowers, Mike Rose, Megan Staples, and Richard Lesh for their thoughtful editing advice. An earlier version of this article was presented at the 2004 Annual Meeting of the American Educational Research Association in Chicago.

Requests for reprints should be addressed to Julie Gainsburg, Secondary Education Department, Michael D. Eisner College of Education, California State University, Northridge, 18111 Nordhoff St., Northridge, CA 91330

Key words: Modeling; engineering; everyday mathematics; workplace mathematics; learning in context. 


\begin{abstract}
Math-education reformers encourage the incorporation of mathematical modeling activities into K-12 curricula. Many of the purported educational benefits derive from the authenticity of the activities — how well they reflect the everyday and occupational mathematical practices of adults. But a paucity in the literature of observational descriptions of adult modeling behavior has made it difficult to judge the authenticity of classroom activities and their potential to prepare students for out-of-school problem solving. The ethnographic study reported here investigated the everyday problem-solving activity of structural engineers in practice. Modeling was found to be central to and ubiquitous in the engineers' work, giving rise to some of their greatest intellectual challenges. These engineers use, adapt, and create models of various representation forms and degrees of abstraction. Two major challenges of modeling emerged: understanding inaccessible phenomena and keeping track of models. These challenges, and the nature of engineering models themselves, are not well reflected in the modeling tasks typically prescribed for the K-12 classroom, which will likely limit their educational benefits.
\end{abstract}


The Mathematical Modeling of Structural Engineers

Modeling in the Real World and the Classroom

"One of the most powerful uses of mathematics is the mathematical modeling of phenomena.” So states the NCTM in its Principles and Standards for School Mathematics (2000, p. 39). Accordingly, a central tenet of math-education reform is to include mathematical modeling in the K-12 curriculum (NCTM, 2000; Lehrer \& Schauble, 2003). Put simply, mathematical modeling means translating a real-world problem into mathematics, working the math, and translating the results back into the real-world context (Gravemeijer, 2004). In practice, classroom modeling activities usually involve applying taught mathematical techniques and representation systems in order to make sense of data, to express patterns, and to generate additional data.

According to the NCTM (2000) and others (as cited), classroom modeling activities have many potential educational benefits. Because they represent a key practice of mathematicians and scientists, modeling experiences give students a fuller understanding of these disciplines (Carpenter \& Romberg, 2004). Modeling is, in turn, a vehicle for other important mathematical practices, including solving problems that require higher order thinking skills (Lesh, Lester, \& Hjalmarson, 2003), understanding and making connections among mathematical and other concepts (Greeno \& MMAP, 1997; Gravemeijer \& Doorman, 1999), and representing and communicating mathematical ideas using various formal and informal methods (Lesh \& Doerr, 2003; Gravemeijer \& Doorman, 1999). Modeling tasks can compel students to be reflective and metacognitive about their solution methods (Lesh, Lester, \& Hjalmarson, 2003; DaPueto \& Parenti, 1999) and to justify claims about quantities and their relationships (McClain, 2003). 
Modeling is also seen as a way to promote the development of a student's mathematical identity and power (Middleton, Lesh, \& Heger, 2003). Modeling activities can give students greater autonomy over the choice of method and determination of the quality of their solutions than do traditional, short mathematics exercises (Lesh, Cramer, Doerr, Post, \& Zawojewski, 2003). The use of real contexts may further empower students by permitting them to draw on personal nonmathematical expertise or knowledge (Carraher \& Schliemann, 2002; Tate, 2001). ${ }^{1}$ And by demonstrating math’s utility for solving problems related to their lives, modeling may encourage students to construct identities as people who should and will use mathematics (Boaler, 1999).

Other benefits of modeling derive from its real-world aspect. Modeling realistic physical, social, or work-related phenomena may engender a deeper understanding of them (Lehrer, Schauble, Strom, \& Pligge, 2001). Modeling experiences are expected to enhance students’ ability to transfer mathematical tools to novel problem-solving situations (Cognition \& Technology Group at Vanderbilt, 1990). Students are presumably motivated by the connection to real contexts. And to the extent that classroom modeling authentically reflects out-of-school practices, it should prepare students for adult life and work (National Research Council, 1998; Forman \& Steen, 1995). This last claim is apparently truer than ever in the modern workplace. Computer-based technologies are assumed to have reduced the need for workers to perform routine calculations but increased the requirement to solve more complicated, non-routine problems that involve analyzing, interpreting, and finding patterns in data as well as constructing, describing, explaining, and manipulating complex systems-all activities associated with modeling (Lesh \& Doerr, 2003). 
Educators, however, have much to learn about how realistic these potential benefits are and how to design and implement classroom modeling tasks that best yield them. Among the critical questions that need to be answered are two that are addressed in this article:

1. Are claims about the importance of modeling warranted?

2. What does adult mathematical modeling look like?

Are Claims about the Importance of Modeling Warranted?

Much of the rationale for modeling in the classroom presumes its importance in realworld occupations. Yet the existing research paints conflicting pictures about the centrality of modeling in adults' everyday problem solving, opening to question the warrant for this curricular reform. In the genre of everyday-math ethnographies (e.g., Lave, 1988; Scribner, 1984; De la Rocha, 1985; Nunes, Schliemann, \& Carraher, 1993), modeling is scarcely evident. Indeed, these studies expose such a wide gap between scholastic and real-world mathematics as to cast doubt on the preparatory value of school mathematics in general. For example, when solving quantitative problems arising in grocery shopping and home food preparation, adults do not employ general, school-taught arithmetic algorithms (Lave, 1988). Instead, they draw from a limited repertoire of known, situation-specific calculation procedures, leading researchers to conclude:

Mathematical practice in work settings is primarily a matter of interaction with instruments and procedures in which relations of quantity and their transformations are stored, and only rarely occasions on which mathematics is relearned, discovered or reinvented.... [T]here is no open field for the employment of mathematical problemsolving skills. (Lave, Smith, \& Butler, 1998, p. 76) 
Somewhat in contrast, Nunes, Schliemann, and Carraher (1993) observed Brazilian street vendors actively constructing mathematical strategies to solve problems arising in everyday selling transactions. In their view, everyday problem solvers adapt or "recontextualize" previously learned arithmetic techniques to new problem contexts (Carraher \& Schliemann, 2002). This view of adult mathematical behavior warrants more optimism than that of Lave et al. about the capacity and disposition of adults to translate real phenomena into standard, abstract mathematical representations. Still, the general arithmetic procedures observed in these studies fall far short of the complex processes that educators consider modeling.

Why is modeling nearly invisible in everyday-math ethnographies? Perhaps their focus on solution-generating activity (or even, ironically, on the comparison with school-type math) has prevented these researchers from detecting and reporting other activities that might count as modeling, such as describing, interpreting, and explaining quantitative relationships and patterns, making predictions, or developing reusable solution methods (Lesh \& Yoon, 200X). Indeed, definitions of modeling, for both the classroom and the real world, vary and are imprecise tools for identifying modeling in research. Another explanation is that most everyday-math ethnographies have investigated low-tech occupations that are known to involve little math; the workers there truly may not tend to engage in modeling. The handful of ethnographies of hightech workers, however, makes their modeling activity hardly more evident. A few studies of scientists (Lynch \& Woolgar, 1990; Latour, 1987; Roth, McGinn, \& Bowen, 1998) demonstrate the central role of inscriptions, a general construct comprising a range of representational forms including mathematical models. But these reports focus in particular on the use of simpler inscription forms - tables, diagrams, graphs, and maps. Other ethnographies (e.g., Smith, 1999; Stevens, 1999; Stevens \& Hall, 1998; Henderson, 1999) emphasize the need for technical 
workers to translate between three-dimensional objects and two-dimensional representations. Together, these studies stress the general importance in high-tech work of fluency with symbolic translations of real phenomena, but they describe fairly basic representational activity and say little about the use or creation of models.

More is written directly about modeling in engineering than perhaps any other field, and here conventional wisdom assigns modeling a key role. Perlow and Bailyn (1997) reported that practitioners across engineering fields perceive the "real" work of engineering to be mathematical modeling, theoretical analysis, and conceptual problem solving. Engineering educators apparently agree. When convened to discuss the mathematical preparation of engineers, professors in four engineering fields all claimed the construction of mathematical models was central (MAA, 2000). This view is not new: in his classic 1956 engineering textbook, Crandall wrote, “The most difficult step in the whole process of engineering is that in which a mathematical model is substituted for a real physical system. It is here that judgment, experience, and ingenuity of the highest order are required of the analysts” (p. 1). Even so, empirical evidence of engineers’ modeling activity is sparse and contradictory. Bissell and Dillon (2000) contended that modeling is a central practice of engineers across professions but not based on systematic observations. The Society for Industrial and Applied Mathematics (SIAM, 1998) reported that the managers of masters- and PhD-level mathematicians in industry jobs value these employees primarily for their ability to create mathematical models. This finding implies that modeling is important to high-tech companies but requires advanced mathematical training and is not normally accomplished by engineers, scientists, or other nonmathematicians. (Not only does this finding downplay the role of modeling in engineers' work, it also raises the possibility that reformers underestimate the difficulty of teaching mathematical 
modeling to K-12 students.) One study (Kent \& Noss, 2002) that did include extended observations of practice, in a large civil-engineering firm, showed that the development of models and high-level mathematical analysis are increasingly passed to mathematics specialists, shifting the engineers' concerns to the more qualitative aspects of received models.

In sum, the strong rhetoric from educators about the importance of mathematical modeling in adult occupations is not clearly supported by research. Needed are ethnographic studies that specifically examine the role and nature of modeling in fields where it is expected to be central, namely science and engineering. Such studies will not only help assess the urgency of this reform tenet but will answer the question: What does adult mathematical modeling look like? The study reported in this article aimed at these goals by investigating the modeling activity of structural engineers in everyday practice.

What Does Adult Mathematical Modeling Look Like?

The research I have just reviewed offers a mix of possible pictures of adult modeling activity—from creating original models for solving problems, to selecting or adapting received, general models, to avoiding models altogether in favor of situation-specific routines and representations - but no consensus about which is most accurate, when, and for whom. Even the literature making the strongest claims about adults' use of models nevertheless provides little description of the nature of those models and the activities and skills their use requires. This is a predicament for educators who want to design classroom modeling tasks with some confidence that they resemble (and prepare students for) adult practices. With many of the purported benefits of modeling exercises hinging on their authenticity, a clearer picture of adult modeling is critical. 
Various authors (e.g., Pollack, 1997; Bissell \& Dillon, 2000; Edwards \& Hamson, 1989; Lesh \& Doerr, 2003) have theoretically outlined the mathematical modeling process with considerable similarity. The following (cyclical) set of steps synthesizes their versions:

1. Identify the real-world phenomenon

2. Simplify/idealize the phenomenon

3. Express the idealized phenomenon mathematically (i.e., "mathematize")

4. Perform the mathematical manipulations (i.e., "solve" the model)

5. Interpret the mathematical solution in real-world terms

6. Test the interpretation against reality

The traditional K-12 mathematics curriculum, with its emphasis on symbol manipulation, prepares students mainly for Step 4, performing mathematical manipulations. Ironically, evidence exists that this is the least challenging step for engineers and that the calculation techniques required here are fairly elementary (Bissell \& Dillon, 2000). My study bears this out; for example, in the vignette presented later, the calculations that the engineer uses to analyze his model only involve the four basic operations, squaring, and taking 5\% (and a spreadsheet handles most of these). In fact, after analyzing the kinds of mathematics used by the engineers across my study, I found that the majority of the topics are normally taught by ninth grade. Apparently, structural engineers' everyday modeling rarely calls for advanced calculation techniques.

The important questions about modeling activity, then, concern other steps of the process. First, to what extent do engineers actually engage in these other steps? The everydaymathematics literature equivocates about whether adults primarily create, adapt, apply, or avoid mathematical models, and specific inquiries into engineering are nearly as inconclusive. 
Certainly in structural engineering models abound—obvious examples being the drawings received from the architect and the conventional, theoretical idealizations of structural elements (like "beam” and “truss”) and their behavior, which permeate engineering texts, lectures, and commercial software. But how well do these examples represent the range of models used in structural engineering? To what degree are engineers personally responsible for creating, adapting, and evaluating models? And if the calculation techniques required to "solve" structural models are cognitively trivial, what are the real intellectual challenges posed by the modeling in engineering work? These questions are critical for the design of K-12 (and engineering) curricula and they guided the analysis in my study.

\section{Methods}

\section{Data Collection}

This study was part of a larger research project to characterize the full range of mathematical behavior of structural engineers at work and its relationship to school mathematics. I used ethnographic methods of data collection and analysis to capture cognition in practice (Lave, 1988). In total, I spent 70 hours in the offices of two firms, observing engineers as they went about their normal, everyday work designing buildings. A cognition-in-practice stance presumes that cognition is situated (Greeno \& MMAP, 1997), that is, shaped by and inextricably grounded in its surrounding context. To increase my ability to detect, understand, and document the context of the engineers' mathematics, I organized my observations and analysis around four extended work tasks (two per firm), selected as characteristic of structural design work. Each task spanned several days, presented a wide range of quantitative problems, required the use of various technological tools, and involved multiple engineers, novice and expert. In all, I followed 
nine engineers extensively: the five junior-level engineers assigned primarily to the tasks and the four senior engineers who supervised them.

Data collected included field notes, audiotape transcripts of nearly all dialogue, copies of artifacts generated in practice (drawings, documents, calculation sheets, spreadsheets, etc.), the engineers' written and oral answers to questions I posed immediately after observations, and audiotape transcripts of 24 hours of interviews. I relied heavily on the engineers to explain their work and thinking, which they did as they worked, later in interviews, and in confirming or revising my written accounts of their problem solving.

\section{Development of Contextualized Cases}

My analytic process comprised multiple interpretive passes through the data. In earlier passes, my goals were to understand the nature of the quantitative problems facing the engineers and to accurately describe the steps of their solutions. From this initial analysis, I constructed four cases — coherent, narrative accounts of the engineers' problem-solving activity in each task that captured social, cognitive, and resource contexts. These cases became the main data form for subsequent interpretive passes. I developed category codes to represent the kinds of mathematics used, then coded each case accordingly. Through repeated, comparative readings of the cases and a close analysis of the major problem-solving episodes in each task, I then derived larger themes and patterns relevant to prior research about the relationship between school and everyday math. The cases also played a critical validating role. The main engineers on each task read the appropriate case and confirmed, revised, or augmented my interpretation of the events, especially their problem-solving approaches and steps and the rationale behind them.

A major theme to emerge from this analysis was the ubiquity of mathematical models; subsequently, I reanalyzed the four tasks specifically for the engineers’ modeling activity. Next, 
after summarizing my findings, I present my analysis of this modeling activity through a detailed interpretation of a vignette from one case.

\section{Summary of Findings}

For context, I first offer a brief introduction to structural engineering. In the course of a building project, the structural engineer's job falls between the jobs of the architect and the companies that fabricate the materials and erect the building. Most of information the engineer needs arrives in the form of architectural drawings, which show how the building should look, its dimensions, and where major columns or walls may be placed. The engineer's main job is to select or design every element of the building's structural system. The engineer's products are a set of drawings conveying the exact elements (beams, columns, etc.) and their means of connection, and a packet of calculations proving, according to engineering theory, that the structure will support the required loads and satisfy official building codes. Structural engineering work is generally framed in terms of design and analysis, words that have definite theoretical meanings but in practice are often nearly inseparable. Design refers to decisions about what elements and connections to use, while analysis is the quantitative evaluation of the performance of the proposed structure. Usually, design and analysis proceed in close iterative cycles, whereby a design or a refinement is immediately analyzed, further refined on the basis of the analysis, reanalyzed, re-refined, and so on.

In my observations of their everyday work, I found that structural engineers employ a wide variety of kinds of models, ranging from concrete and literal depictions of structures or elements to abstract and fragmented representations of structural behavior. Structural engineers engage in every aspect of modeling—selecting, applying, adapting, and even creating models— though not necessarily during any single task. Structural engineers can sometimes make use of 
received models, but the uniqueness and complexity of each building project make it impossible for the industry to cover all circumstances with established models, and a significant amount of localized model creation and adaptation is left to the engineer. Structural engineers are sometimes required to devise original mathematizations to analyze structures and their behavior. Other times, the mathematizing step is trivial: the appropriate formulas or mathematical representations have already been determined and are manifested in established theory or analytic software packages. For example, once an element or structure is conceptualized as a beam, engineering theory provides the idealized form and associated equations for calculating stiffness, deflection, moments, and other conditions and behaviors. ${ }^{2}$

Within the engineers' modeling activity, two particular challenges emerged: understanding the phenomenon to be modeled and keeping track. I summarize these next. Understanding the Phenomenon to be Modeled

In the majority of modeling exercises presented in the K-12 math-education literature, the phenomenon to be modeled exists and is accessible to the student. For example, students are provided with a table of prices for cell-phone calls or daily temperatures, or they measure the heights of a bouncing ball; then they symbolically represent patterns they discern. In contrast, structural engineers engaged in design work do not have the luxury of actual data or accessible phenomena to measure, because the objects of their designs do not yet physically exist. This presents a chicken-and-egg problem: the proposed design must be informed by an analysis of its behavior, but analysis cannot occur until there is a design to analyze! Even in the rarer case when an engineer is contracted to evaluate an existing structure, she lacks the kind of access to the building and the lab equipment she would need to gather empirical information. Sitting in her cubicle, she is still, for all practical purposes, modeling hypothetical entities and referring to 
design drawings and theoretical representations of elements and their behavior. With the subjects of her model—the forms and behaviors of the proposed elements and structures—essentially inaccessible, she must construct some conceptual version of those phenomena as a stand-in for reality and a means for generating data. Understanding inaccessible phenomena in order to model them can be a significant challenge for the engineer, although it does not appear per se in the theoretical modeling cycle. (It seems likeliest to fall under Step 1).

\section{Keeping Track}

Many characterizations of engineering practice, particularly those intended for laypeople, mention only its most concrete, literal, and coherent models, namely the drawings that indicate dimensions and materials. But many of the models used by the engineers in this study were abstract and theoretical. Some were fragmented, their representation and storage distributed in parts among multiple artifacts, with some parts only existing conceptually. It is easy to point to a model that is completely captured in a drawing, and there is no mistaking lines on paper for the concrete, steel, or wood elements they represent. But working with the more elusive and abstract models requires a constant mental bookkeeping effort, and occasionally this effort can overwhelm. In a few instances, I observed engineers losing track of which model was being referred to in conversation, forgetting which assumptions had been justified or were necessitated by other assumptions, and even confusing model with reality. Keeping track appears nowhere in the theoretical modeling cycle, although it is a challenge that can arise at any step.

In the next section, I present an extended vignette to illustrate the nature of structural engineering modeling and its challenges.

Vignette: The Challenges of Modeling a Wood Floor

\section{Background}


This vignette follows the work on a four-story, wood-framed, residential complex, Spring Valley Apartments. Tim ${ }^{3}$, a junior engineer, is analyzing the building’s lateral system, the subset of structural elements designed to resist external horizontal load (in this area of the country, from earthquakes; elsewhere, typically, wind). In the Spring Valley Apartments, the elements of the lateral system are extra-strong, or "shear" walls, about 100 on each story. In lateral analysis, the engineer determines how a predetermined external load becomes distributed to the individual elements of the lateral system. Tim has previously written a lateral-analysis spreadsheet, which takes as input the overall, external lateral load and various properties of each wall and outputs the internal forces that result on each wall. When a lateral force hits a wall aligned in the same direction, the wall has a tendency to overturn, or cartwheel over. This overturning causes the far edge of the wall to compress and the near edge to pull away from the floor. To resist these forces, devices called tiedowns are installed in the edges of the shear walls. Tiedowns are constructed of wood posts, to resist the compression, and steel rods, to tie the wall to the floor.

This morning Tim faces a problem: according to his spreadsheet, the compression forces on the ends of a few walls are so high they exceed the capacity of any reasonably sized tiedown post. These large forces occur in the central, four-story core of the building (other areas have only three or two stories). Tim plans to explore two solution approaches, one structural and one theoretical. The structural solution involves finding additional architectural walls that could be constructed as shear walls, to help handle the overall load. In contrast, the theoretical solution aims to re-describe, or remodel, the behavior of the lateral system such that the resulting analysis would show a more evenly distributed load, even though no physical changes would be made. Yesterday, Tim’s supervisor, Eric, had suggested the remodeling approach but offered little detail or direction. Tim explains to me that the behavioral model currently reflected in his 
spreadsheet assumes that the compression force on a given upper story wall will only travel directly downward into the wall located immediately below it, adding to the compression in the lower wall. This assumption considers the floor, or "diaphragm," to be "infinitely flexible," that is, too rubbery to transmit any forces laterally, from the upper story wall to a lower story wall located any horizontal distance away. The opposite assumption would treat the diaphragm as “infinitely rigid," capable of complete lateral force transmission. In that case, the force from an upper story wall would be distributed evenly to every wall on the story below, regardless of its horizontal distance from the upper wall (Figure 1). ${ }^{4}$ Both assumptions are actually impossible extremes. Reality lies somewhere in between—wood floors are partly rigid and will laterally transmit wall forces to some degree.

[Insert Figure 1 about here]

To be conservative, Tim had programmed his spreadsheet to reflect the behavior of an infinitely flexible floor, summing all compression forces vertically down through the building and transmitting none laterally. Because this model concentrates the compression forces into a few walls rather than spreading them out among all walls, it produces more extreme high forces and thus compels a stronger building design. But with the spreadsheet reporting post-crushing forces, Eric had advised Tim to try the alternative assumption—what Tim calls the "everybody gets some" model—of an absolutely rigid floor. The sections that follow trace Tim's efforts to remodel the floor and solve the problem of high wall forces.

\section{Trying to Understand the Phenomenon}

Tim begins by trying to grasp the idea behind the new model. He tells me he had been surprised by Eric's suggestion to model the floor as rigid, because he cannot quite fathom why a 
wall would not always transfer its entire force to the wall directly below, with which it essentially forms a single element, no matter what the condition of the diaphragm: ${ }^{5}$ I was a little incredulous, 'cause I figured if there's a direct load path in a wall, why is it going to use the diaphragm, you know? But it's actually, it's not—-[to himself] Let's see-Yeah, yeah, it’s a little weird to me. 'Cause the floor force, I could see, you know, you're pushing on a floor, it's gonna have these things underneath it and it's going to go to the things that are giving the most resistance, but when you're coming down with the wall, I don’t know.

He continues: "So what Eric is saying is that this is a stiff element also, this floor, and to ignore it completely isn't really capturing the problem.” Tim sketches a simple floor plan of the building, with a shaded four-story core and two outlying areas with three stories (Figure 2). He says he can imagine that walls in the three-story area located near the four-story core would receive some of the forces from core walls by transmission through the floor. But he finds it hard to believe a wall near the outer edge of the building would "see some of that weight" from the core, "because it's got a long way to travel to get there. So, in reality, the distribution of these forces is very complicated. It’s not gonna be uniform.”

[Insert Figure 2 about here]

Apparently, much work may remain for the engineer even when established models are available. Two conventional methods exist for modeling lateral-force transmission through a wood floor, but each incorporates an unrealistic idealization. Tim initially feels more comfortable with the flexible model because it more closely approximates his understanding of actual floor behavior. Also, this model is safer because it produces an analysis with higher wall forces than actually expected. Tim can talk himself only into accepting partial transmission: to 
nearby walls but not to remote ones. Even though the rigid model is industry-established, Tim, like the other engineers I observed, resists using a model he cannot justify with his knowledge of real behavior.

\section{Beginning to Mathematize}

Tim presumes that the results of the infinitely rigid floor analysis will not actually be used for design. If he eventually abandons the flexible-floor model, he expects he will have to develop some in-between model that captures the complicated, non-uniform force distribution. Eric had not explained how to develop an in-between model, but Tim believes there is a logical way to do it. Meanwhile, analyzing the rigid model is just an experiment that Tim acknowledges is "not really accurate.” Tim describes to me what this experiment will offer and predicts how he will use this information, though his uncertainty is apparent:

By doing it that way, we'll have an envelope and at least know that the real solution is somewhere between those two.... And so what we'll probably do in the end is some kind of shell game with the loads, so that in order to get the building built, we'll say, well, we know it's not going to go rigidly and it's not going to go zero [transmission]. It's going to go-We're going to make some boundary decision, maybe, I think, to be simple. And say these walls will contribute. And we'll be able to-I mean, the way to do it is to work, again, with the relative rigidity, because the diaphragm has some rigidity and you could calculate that- [To himself] It's just not done that way.

Here, Tim starts to grapple with the impending mathematization. He considers how to develop a model that will reflect partial horizontal load transmission and lead to a more accurate “solution,” or set of wall forces, that lies "somewhere between” the extreme solutions that bound the “envelope.” From here on, Tim focuses on the transmission of loads from the central, four- 
story core of the building to the walls in the three-story areas that surround this core. His initial idea is to draw a somewhat arbitrary region around the core; the three-story walls located within this region would receive transmitted forces from the core while those outside would not. But Tim is unsure how to determine that region and he doubts that an established mathematization exists. Tim's uncertainty, it should be noted, is not about which mathematical rules to apply to describe a phenomenon. His difficulty lies in understanding the physical phenomenon itself: he does not know how forces from the upper walls actually move through the wood floor to the lower walls. Finding the envelope solutions is a strategy to sidestep this lack of knowledge. These two solutions—-possible to find but inaccurately representing the situation—will give Tim a rough shape of the answer he seeks. He hopes to somehow work inwards from these endpoints towards an accurate solution and avoid having to completely understand the floor's behavior to build a new model from scratch. ${ }^{6}$

Tim now considers how to mathematize the rigid assumption for a new spreadsheet algorithm. Quickly, he discovers that only a simple modification to his existing, flexible-floor spreadsheet is necessary. His current spreadsheet sums the load on an individual wall only with the load on the wall directly above it. To adapt it for the rigid assumption, he needs only to reprogram it first to sum the loads from every wall on a story and then to distribute that lump sum to the walls on the story below, in proportion to their stiffnesses. A colleague has already written a spreadsheet that accomplishes this proportional force distribution, and Tim can link his spreadsheet to that one.

This episode shows that mathematizing is sometimes a relatively simple part of the modeling process. But it also illustrates a paradox of math-based technology: its simultaneous power and weakness. Using a spreadsheet, Tim can change his model dramatically, reanalyze 
400 walls, and generate hundreds of new force values, all in a matter of seconds with relatively little mental effort. Yet this powerful technology tool offers no direct information about the physical behavior he wants to model. It will carry out physically inaccurate analyses as easily as accurate ones, yielding no clues about the validity of the underlying assumptions. Without the spreadsheet, Tim could not generate the envelope, yet the spreadsheet gives no information about how to use the envelope to close in on the desired solution.

\section{Keeping Track}

Seeing how easy it will be to modify the spreadsheet for the rigid-floor model, Tim shifts his attention for the next half hour to the structural solution, which involves removing and adding shear walls. He first back-calculates the maximum force that could be handled by the largest reasonable tiedown post that would fit in the walls. He then identifies a few purely architectural walls that could be reinforced to become shear walls and he adds them to his spreadsheet. Finally, he removes from the spreadsheet any wall displaying a force exceeding the maximum (because the wall would be unable to support that force). Unfortunately, these changes only move the problem around; Tim has merely pushed the forces on other walls above the maximum.

As Tim attempts both structural and theoretical resolutions to the problem of high wall forces, he shuttles between models of different natures. His task, like all structural design work, obviously depends on descriptive models—drawings—of the building, to which he turns repeatedly for information about the structure. But more levels and types of models have come into play. Central to Tim's work are models of the lateral resistance system. On the most concrete level, the lateral system is a physical entity: a subset of the building's beams, columns, walls, and connections working together to resist lateral load. Because the Spring Valley Apartments do not yet exist, neither does this instantiation of the lateral system. What does exist, 
one level into abstraction, is the idea of this system, Tim's conception of a substructure that resists lateral load. This conceptual structure is a model that comprises idealized, theoretical representations of selected elements (for example, beams that are perfectly straight and uniformly dense) and the assumption that they, and only they, will contribute to the building's lateral resistance, up to but not beyond their theoretical capacities.

I never see Tim or Eric depict this theoretical substructure per se in a drawing. Where, then, does this model reside? It is actually distributed in pieces over several locations. In Tim's mind are the general categories of elements involved (namely, the floors and any wall over 4' long) and perhaps a three-dimensional image of layers of floors connected by shear walls. Which specific walls are included in this model are recorded in unofficial keys Tim created by labeling each shear wall with an ID number on photocopies of the floor plans. Tim's spreadsheet also houses parts of the model by displaying the ID number, location, and dimensions of every shear wall. The model even resides partly in codebooks and manuals, where Tim can find empirical information (capacities and sizes) for standard elements that approximate the idealized ones in his system. Unlike the drawn models of the building, the model of the substructure known as "the Spring Valley lateral system" is physically impossible to point to. Tim must mentally link the distributed parts to keep track of the model as a whole.

In addition to this model of the lateral system's structure, Tim's work invokes a model of the behavior of the system under lateral loading and of the flow of forces through it. This behavioral model moves further into abstraction by adding another layer of idealization, this one involving assumptions about structural reactions and interactions. For example, Tim assumes that long, thin elements will behave in perfect accordance with classic beam theory and that the lateral load will distribute itself to the walls in exact proportion to their stiffnesses (themselves 
idealizations). Like the structural model, this behavioral model is distributed, impossible to point to, and never explicitly drawn, except in the few informal sketches Tim and Eric make as they explain isolated behaviors to each other and me. Some of the model resides in agreed-upon propositions or rules about behavior, such as the stated assumption of a rigid diaphragm or codified beam theory. The spreadsheet, again, stores part of the behavioral model as formulas for distributing the forces according to established rules. Metaphorical terms help capture and tie together behavioral models. Structural engineers frequently refer to "load paths," indicating that behavioral models are partly held in mental images of idealized routes (e.g., straight lines or triangular "fans”) along which forces translate through a building. Indeed, Tim and Eric use the terms flow, travel, rubbery, mush, shedding, and everybody gets some. Some of this graphic metaphor is universal. Engineers in both firms spoke of lollipops when describing the oscillation patterns of a low, wide building in which heavy floor masses (the "candy") were joined by lighter walls and columns (the "sticks"), suggesting, as one engineer did directly, that this metaphor is taught in schools. Bucciarelli (1994) noted that engineers use metaphors to "gain control and to master the object [of design] on his or her own terms” (p. 88). ${ }^{7}$

A key distinction between Tim's two approaches to the wall-force problem is that they concern different types of models. Adding and subtracting shear walls is a modification of the structural model. The theoretical approach modifies the behavioral model by changing the agreed-upon rules about the flow of forces. Tim must keep track of which model type his modifications target, making sure to hold all other assumptions constant. This kind of trackkeeping effort can be complicated by inconsistencies within a single model type. In fact, Tim’s behavioral model harbors a major inconsistency: the floor is presumed to transmit no wall forces laterally but to transmit torsion forces ${ }^{8}$ laterally. Thus, Tim's spreadsheet treats the floor as 
simultaneously rigid and flexible—rigid for torsion and flexible for wall forces. This impossible (but professionally accepted) hybridization illustrates the theoretical, idealized nature of some engineering models and why considerable effort may be required to keep track of assumptions, which, even in a single model, may conflict.

Another potentially confusing factor is that, in design work, causality between model and reality is reciprocal. Real structural features and behavior obviously influence how the structure is modeled, but decisions made at the model level in turn dictate features of the actual structure. Attempting a structural solution, Tim "shortens" and "removes" shear walls simply by changing or zeroing out their lengths in his spreadsheet. The impact of this mathematical change on the building's design is partly real. An actual wall will be built to the dimensions originally specified by the architect. But the "shear wall," the theoretical, idealized portion of the wall that resists lateral load, will be shortened or removed by changing the wall's construction: shortened by moving the tiedowns inward from the wall's ends or removed by eliminating the tiedowns and extra plywood paneling altogether.

The reciprocal influence between model and structure, and its potential for confusion, are even more clearly illustrated later in the project, when the architect calls for some walls to be shorter on the fourth story. Tim must decide whether to use two tiedowns, aligned with the edges of the short, upper wall and running down through all stories (Figure 3) or introduce a third tiedown on the lower stories at the ends of the longer walls (Figure 4)? The first design is cheaper but runs a theoretical "cut" down the lower walls, thus reducing their shear-wall length. After he makes his decision, for the duration of the project Tim must keep track of what he has modeled, what is real, and what aspects of reality can and cannot be incorporated into the model in the future. He must remember that his spreadsheet will show "lengths" for some "shear walls" 
that differ from the lengths of the real walls on which they are physically manifested. If more resistance is needed later, these shear walls can be lengthened by increasing their dimension in the spreadsheet, or brought back into existence by changing their spreadsheet lengths from zero.

[Insert Figures 3 and 4 about here]

\section{Trying, Again, to Understand the Phenomenon}

With the structural approach (adding and subtracting walls) having failed to produce a feasible design solution, Tim consults Eric about changing the model of the floor's behavior. At this point, the men understand the problem as follows: The flexible-floor model can be justified because it is conservative, but it does not work—some of the resulting forces exceed the capacity of the tiedown posts. They expect the rigid-floor model, the opposite extreme, to produce manageable forces, but they know it is inaccurate and may not be justifiable. The real floor will transmit some degree of force, perhaps enough to reduce the problematic wall forces sufficiently, but without knowing exactly how much transmission will occur, the men cannot systematically model it. They now discuss how to find a solution between the extreme models:

T: $\quad$ And then it'll be an assumption of, you know, infinite rigidity of the diaphragm, and it'll be sort of an envelope of the problem. And then we can see-

E: $\quad$ And then it's a judgment call—

T: $\quad$ Yeah, if-

E: —what's appropriate-

T: $\quad$-how to design the walls that are-Yeah, 'cause it's somewhere in between those two. And the walls that are near the core that are three-story are going to get more of the burden than the walls that are away from the core-

E: $\quad$ [Pointing to walls on a drawing] Yeah, I mean these guys- 
T: $\quad$ So maybe what we'll do, then, is make an arbitrary designation, you know, anything east of there [pointing on the drawing] is not going to help us and east of here is not, and these walls, we'll make extra tough, so that—you know what I mean? — the four-story portion will travel through the diaphragm to here, and then it will stop.

E: $\quad$ [After a pause, with reservation] Yeah.

T: $\quad$ No?

E: I understand what you're saying. It's going to be hard to-

T: I'm trying to find a way to do it, you know, conservatively, so we don’t end up underdesigning these walls and overdesigning those.

Tim's concern is that, with a completely rigid assumption, three-story walls near the fourstory core will be "underdesigned," designed to be too weak, because the analysis will underestimate the force they receive from the core walls nearby. He also worries that the threestory walls far from the core will be "overdesigned"—made stronger than necessary—because the analysis will incorrectly assume core forces will reach them (Figure 5). By proposing to designate a region of transmission around the core, Tim jumps ahead to a possible strategy for mathematization. But Eric reels him in, implying that they do not know enough about the actual behavior of the floor to rationally determine such a region. Instead, Eric foresees making a “judgment call” on a final design, presumably based on past experience with similar structures.

[Insert Figure 5 about here]

This episode reveals a further complexity of the two models. Though Tim does not frame it in these terms, the envelope solutions, in an important sense, are not pure extremes. It is true that an absolutely rigid floor would even out the wall forces and produce a less conservative solution overall. But for walls far from the four-story core, the model is actually more 
conservative because it presumes core forces will be shared with these remote walls. In reality, the partial flexibility of the diaphragm will impede such widespread transmission, hence Tim's concern that remote walls will be overdesigned. The converse, that the conservative, flexiblefloor model has less conservative aspects, is also true, though neither Tim nor Eric articulate it here. In the flexible model, walls near the core are assumed to receive no core forces, when in reality the partial rigidity of the floor would transmit some force to them. As a result, by adopting the more conservative model overall, the near-core walls would be designed too weak. In their conversation, Tim and Eric must not only keep track of which of the two models they are talking about but also of the problematic assumptions within each model that fail to capture reality and must be corrected for.

The in-between solution left unresolved, Tim returns to his cubicle and modifies his spreadsheet for the rigid-floor assumption. As predicted, he finds that all the wall forces now fall safely under the capacities of the tiedown posts. Later, when Eric hears the rigid model has produced a "reasonable" set of forces, he replies, "Now we need to somehow justify that it works.” He suggests they reconvene to work on this problem, to "take a look at the drawings, see how realistically [the forces] can spread out, and maybe if they can't, maybe there's some other ways we can kind of trick our model to account for these things.”

\section{A New Model}

Meeting that afternoon, Eric and Tim examine the building and try to figure out how lateral load would actually travel through it. Of course, they have no actual structure to push on and measure resulting forces; they rely on the drawn models of the Spring Valley Apartments and on their general knowledge and intuition about the reactions and interactions of various elements. But they now refer to more complex renditions: detailed, official, 11”x17” drawings 
that depict the floors' irregular shapes and weight distribution. The men describe the floors to each other, story by story, to assess the quality of their vertical and horizontal connections. Using hand gestures, they trace the load path through the floors. Eric points out "jumps," where the floors are discontinuous and would have to be somehow "tied" together to ensure horizontal force transmission. But after much discussion, they can only reach a vague and tentative conclusion about the building's behavior: Forces at the roof level generally will transfer straight down through the building via the four-story walls, not horizontally to other walls, but on lower stories some core forces might spread beyond the core in the north-south direction.

Having apparently exhausted this means of investigation, Eric takes a new tack. He proposes an extremely simplified representation, which he later characterizes as "pure invention.” He models the floor as a single, ideal beam that transfers its entire load to its ends, with no help from any intermediate supports. Sketching a rough outline of the floor, he says, "You could design it as a beam, basically, right? And these are your two chord members, right? ${ }^{9}$ And you track your shear through here, even if it has to go through crazy paths to do it.” He draws two line segments across the main part of the floor, to indicate the theoretical boundaries of the beam. Then he converts his sketch into a classic diagram of a simply supported beam (Figure 6), with a small triangle on each end for the supports and an arrow in the center (labeled V) representing the story shear, or lateral load on that story, as a point force. This sketch not only transforms the entire floor into a single beam but also reorients the view from plan (overhead) to elevation (portrait). The lateral force on the floor, in reality, is horizontal, but the force on a beam is conventionally depicted as vertical.

[Insert Figure 6 about here] 
One advantage of Eric's new behavioral model is its simplicity: it reduces the irregular area of the floor to the largest rectangle fitting within it, whose length and width are taken to be the dimensions of the "beam.” Another advantage is its extreme conservatism. If this beam could be proven capable of transmitting its entire load to its ends, it follows that it could transmit the load to any support points along its length, that is, the interior walls below. That the floor is strong enough to distribute the load in this manner is not sufficient to prove that such spreading will actually occur, but it is a necessary condition. Essentially, Eric hopes to prove one model by proving another, more conservative one. He imagines his beam model will be easier to prove, according to his knowledge of physical behavior, than the rigid-floor model, which he and Tim are finding impossible to justify. Eric tells me later, "This was just a quick check to see are we even in the ballpark? Would this work?” Of course, this quick check has added a new layer of modeling and compelled a new layer of proof.

Tim suspects the wood floor will be too weak for Eric's idea to work, but the men proceed to play the model out. The spreadsheet provides the force at the roof level, and the men assume half of this force would be transmitted to each end of the beam. Estimating the beam's length and depth, they calculate the resulting demand on each lineal foot of plywood at the beam's ends. Despite the absence of a real building, a somewhat empirical test exists: Eric knows the typical strength of this kind of plywood floor. As Tim predicted, the demand they calculate far exceeds the plywood's capacity. Eric's beam model cannot work. Losing Track

Eric informs Tim he will have to stick with the original, flexible-floor assumption. But Tim has now become convinced of the validity and necessity of a model with some rigidity. He laughs as he protests to Eric, 
You're going to give up that easily? I don’t like that solution! ‘Cause it gives me these numbers in the range of 50 kips [50,000 pounds] per tiedown, 45 at the minimum. I mean, I feel less concerned about this now than I did before, because I used to think of 50 kips as 50 kips—-that's what I'm going to have in this element to resist the overturning. But now I realize that's not really what I'm going to have, because that's assuming there is no diaphragm transfer at all. That's assuming that the diaphragm is mush and these walls are all I've got—vertically, but, you know, to some extent. And this assumption of absolute rigidity is also false. Somewhere in between is the actual building behavior. Hoping to salvage some degree of force transfer through the floor, Tim makes a few lastditch attempts to justify rigidity. First, he tries to save Eric's beam model using a common engineering strategy: reducing the model's conservatism through increased accuracy. He ventures that the floor might be stronger because of its special nailing pattern. But when he checks the codebook for the capacity of a floor with this condition, he sees it is still far below the demand of the beam model. Next, Tim tries to connect to other projects he has seen, wondering how they achieved higher floor capacities. Eric explains they used more nails and thicker plywood than Spring Valley. Eric points out that the demand they calculated on the ends of the beam is even too low, because they did not account for a courtyard hole in the floor (the " $\mathrm{X}$ " in Figure 6). Ultimately, the men accept their inability to prove any model involving rigidity and resign to use the original, flexible-floor model. However, as the next excerpt shows, they have different views of what design decisions can now be justified.

Tim remarks that he will just add a note to his analysis to the effect that, "the maximum compression [in the wall ends] is slightly above the allowable, but it's OK by virtue of the fact that the diaphragm has some stiffness and at each level some of the load is shed to adjacent 
walls.” (Adjacent has become their term for three-story walls near the core.) But Eric objects to Tim's assumptions and insists the problem of excessive compression forces in some core walls remains. A confusing exchange ensues as Eric tries to convince Tim that they cannot use lateral force spreading to justify reducing loads, because they have not been able to prove any rigidity:

E: OK, if we leave it as is with your first model, four-story [forces] go all the way straight down, we're ending up with 4-by-12 posts? [These posts are impractically wide.]

T: $\quad$ Yes, if we want to satisfy 625 psi. [625 pounds per square inch is the published strength of the wood tiedown posts.]

E: Yeah.

T: $\quad$ If we don’t care about the $625 \mathrm{psi}-$

E: Well, we have to, right? Why are you saying, "If we want to"?

T: $\quad$ [Pause] No, because the real stresses perpendicular to the grain would be less as a result of this sharing of load from adjacent walls.

E: You're saying the diaphragm spreading?

T: $\quad$ Yeah.

E: $\quad$ Ok, but that's not-OK.

T: I'm saying - Yeah, the numbers that I'm coming up with down here, they show crushing on the foundation sill plate are a little extra conservative and we really have a smaller number due to the sharing of load due to wall—through the floor.

E: OK, but that's what we're trying to prove, and we haven't been able to do that yet, right?

T: $\quad$ OK. So [laughing], I didn’t realize we were still trying to prove that!

E: No, but—Well, we didn't prove it, right? So right now in kind of a Solution A is we just stay with 4-by-12 posts, right? 
Here, Tim proposes arbitrarily increasing the published capacity of the posts, a backdoor method of incorporating into the flexible-floor model the rigidity that he feels certain exists. But Eric argues that, because they could not "prove” any rigid-floor model (i.e., justify an assumption of rigidity), they cannot assume any advantage that rigidity would provide. This would also rule out Tim's proposed note excusing the excessive compression forces with the explanation that the spreadsheet ignores load spreading. Either Eric is applying a higher standard of rationality than Tim, or, in the course of working with and keeping straight the multiple versions of models, layers of abstraction, and forms of justification, Tim has simply lost track of what has and has not been agreed upon. Perhaps sensing the latter to be the case, Eric now organizes their options, both based on a flexible diaphragm.

Option A is to use the impractical 4"x12” tiedown posts in the walls with the largest loads. Option B is a new solution: to ask the architect to thicken these walls by 2" to accommodate 6"x6" posts, which can also handle the highest loads but have a more practical width. The men play out Option B, examining the forces on the spreadsheet printout to determine how many walls would need thickening. Seeing the number to be small, Eric states his preference for Option B but adds that they still have not addressed the adjacent walls. Tim asks why the adjacent walls remain an issue if the spreadsheet is not reporting problematic forces there. Eric reminds him that the spreadsheet is probably underestimating the adjacent walls' loads by assuming no forces transfer from the core.

Earlier, when trying to model the partial spreading of force through the diaphragm, Tim had expressed exactly this concern: that they would underestimate the forces on the adjacent walls. Now that the context has changed and they have returned to the conservative, flexiblefloor model, Tim seems to consider the phenomenon of force-spreading moot and is no longer 
worried about the adjacent walls. He may be ignoring the fact that the flexible model, while more conservative overall, is not conservative for every wall. If Tim interprets the model's conservatism as absolute, it would explain his trust in every force the spreadsheet generates, including those on the adjacent walls. Because these reported forces are within the capacity of a reasonably sized post, why worry about them? Apparently, Tim has automatically tossed out all assumptions associated with the rejected rigid-floor model, regardless of their rationales. Eric, on the other hand, maintains through the transition from one model to another a sense of the structure's actual behavior, and he realizes that some assumptions must be retained. Aware that some load spreading will occur in reality, he knows they must account for the extra demand on the adjacent walls, even though they have adopted a model that rejects load spreading and even though this model is generally conservative. So, as they settle on Option B, Eric announces, "We just arbitrarily bump up these walls here.” He gestures randomly to an area on the drawing to indicate which walls should be strengthened, avoiding any decision about how to systematically determine a region of transmission. The point is subtle: although Eric had warned Tim not to assume any advantages from rigidity, because no rigidity could be proven, Eric now insists on incorporating the disadvantages of the rigidity they know will exist but be ignored by their model. As a general rule, once an analytic model is accepted, the forces it indicates may not be reduced without proof, but they may be increased at will.

\section{Discussion}

On a basic level, this study responds to prior everyday-math ethnographies with something of an existence proof, showing adults not only capable of using formal mathematical models and methods to solve real problems but also willing to do so when the situation calls for it. More specifically, the results affirm the strongest views of the importance of modeling in 
engineering work (e.g., Perlow \& Bailyn, 1997; Crandall, 1956; Bissell \& Dillon, 2000). These engineers made a convincing case that modeling—-transforming hypothetical structures into mathematical or symbolic language for the purpose of applying engineering theory—is the heart of their profession. Modeling presents their biggest intellectual challenges, drives the bulk of their sense-making activity, and defines professional expertise. Structural engineers regularly engage in all steps of the theoretical modeling cycle, as more than just consumers of established models - across the four cases in this study the engineers created models as well as selected and adapted them. The need to create or modify models may seem surprising, given the profession's overt commitment to standardization, convention, and rules. For example, the problem of characterizing the behavior of a wood floor between the extremes of absolute rigidity or flexibility would seem to arise on virtually every wood project; one would think it would have been solved thousands of times by now. Yet when I ask Eric if it were true that no established method exists to solve this problem, he answers,

I would say, no, there is none, in terms of the engineering community. If you went back ten years ago, everything was flexible at that point, and it's only lately that evaluating as rigid diaphragm has come into play. And still, that even has questions as to how rigid it is, so they—it's not very clear which way they'll approach it.

Eric says he has faced this same problem on other projects, and each time it has been resolved differently; "It really is a case-by-case evaluation."

Vincenti (1990) viewed the discipline of engineering as evolving towards greater systematization, as the profession strives to "replace 'acts of insight' (unteachable) by 'acts of skill' (capable of being taught)" (p. 168) by establishing standard procedures and routines. Such systematization, he claimed, is "fundamental to the ability of modern engineering to advance on 
so wide a front," because it permits "the optimum solution of complex problems with minimal dependence on individual genius or insight” (p. 168). Echoing these ideas, Eric's comment sketches the historical development of a profession-wide solution to modeling a wood floor and hints of further systematization to come. Despite these predictions, my observations suggest that structural engineering, for all its codes, manuals, curricula, and theory, is far from arriving at an ultimately routinized state. Until that (unlikely) day when the profession reaches the holy grail of complete systematization, the workaday engineer will confront the challenges of modeling physically nonexistent or inaccessible phenomena. Published, laboratory “push-test” data may be available, but only for standard, simple elements, not the complicated shapes or structural combinations engineers regularly encounter. In fact, the results of this study suggest that modeling inaccessible phenomena is the fundamental problem of structural engineering. Working with models does not always compel the engineer to spend significant time predicting nonexistent phenomena, but each of the four major tasks I observed invoked this challenge at some point.

A primary strategy that engineers use for attacking tough modeling problems is analogy, as Eric illustrated by analogizing the floor as a beam. Nersessian (1991) described analogical problem solving as "a modeling process in which the relational structures from existing modes of representation and problem solutions are abstracted from a source domain and are fitted to the constraints of the new problem domain” (p. 20). Apparently, Eric is in good company; Nersessian identified analogical problem solving as a central process of scientific revolution. In the course of major conceptual change, she noted, “analogies are not 'merely' guides to thinking, with logical inferencing actually solving the problem, but analogies themselves do the inferential work and generate the problem solution” (p. 21). This claim seems to apply to everyday 
engineering work as well as scientific revolution. Once conceived, the beam analogy automatically supplies rules and formulas for characterizing the behavior of the wood floor.

On the other hand, finding an analogy (and its attendant formulas) does not always solve the problem, as Eric’s beam model attests. Mathematical modeling, at least in engineering work, is something of a one-way street. Although an understanding of the phenomenon being modeled is usually crucial to developing the ensuing mathematization, the reverse is generally not the case: mathematization is seriously limited as a resource for predicting structural phenomena. In their analysis of engineering modeling, Bissell and Dillon (2000) contended, "Models have to be mediated and negotiated with a community of practice to make any sense" because "a model of a system is neither the system itself, nor a self-evident representation of it” (p. 6). Moreover, An engineering explanation does not begin and end with a mathematical procedure. The problem with [a mathematical] approach is that it gives little or no insight into how a particular behaviour comes about.... Gaining insight into what is going on in a system requires more than just mathematics, however: it requires a story about the system that suggests reasons for a particular type of behaviour and predictions about what may or may not occur in the future. (p. 7)

Neither mathematics nor modeling technologies can produce information about actual behavior; they can only transform, manipulate, organize, store, and display that information. Kevin, a senior engineer in the other firm, makes this point as he explains the contribution of computer programs to structural engineering:

First of all, all the [computer-generated] answers are wrong because of the assumptions, right? No computer program models the real world accurately. The extent to which it is accurate depends on how well the person that is actually performing the analysis on the 
program understands, one, the assumptions built into the program, two, the characteristic behavior of the actual structure. What an engineer can't do is solve all the simultaneous equations in his head. What he can do is visualize the behavior in his head and understand the behavior. So all you're really looking for, you have to have an understanding of how the building is going to behave, and then you use the computer basically as a tool to quantify that behavior. That's all the computer is doing, is quantifying a behavior.

On first blush, Eric’s purpose for using a model (his beam analogy) might seem to be to understand the behavior of the floor, but, in fact, this case exemplifies the predictive weakness of mathematization. Had this model worked, it would only have provided a boundary value for the floor's capacity but would have offered no new information about its actual force-transmitting behavior. Eric's model is merely a means to transform, reorganize, and display published capacities to better fit the situation.

Given the picture of modeling offered here, the theoretical outline of the modeling cycle is accurate as far as it goes. But it poorly expresses the nature of real-world modeling activity, thus limiting its value as a guide for curriculum design. Of course, this study investigated only structural engineering, but the challenges of modeling there are almost certainly related to those in other engineering and high-tech occupations, especially when design is involved. In the next section, I consider how the findings of this study might inform K-12 curricula.

Modeling in the Classroom

The traditional K-12 mathematics curriculum, with its focus on performing computational manipulations, is unlikely to prepare students for the problem-solving demands of the high-tech workplace exemplified in this study. In a general sense, the incorporation of 
modeling activities into the classroom seems well advised. Unfortunately, this curricular reform as currently manifested in the few texts and classrooms that address it, though a step in the right direction, still appears to fall short. Significant differences between the engineering and scholastic versions of modeling, in kind and degree of complexity, threaten this reform's hopedfor benefits.

Although there is variation, the modeling tasks typically prescribed for K-12 students expose them, at best, to a narrow subset of the modeling activity of engineers. A main goal of the standard school modeling exercise is to determine patterns within data. Access to the data is rarely the problem; if not provided, they can be generated easily with mathematical operations or by measuring real phenomena. Students then express the patterns as general rules, in various forms (words, graphs, diagrams), the ultimate goal being algebraic representation. In a popular example, students discover how many diagonals can be drawn in various polygons and then derive an algebraic rule for predicting the number of diagonals in any given polygon. Thus, school modeling problems are essentially generalization or abstraction exercises. Indeed, generalization problems have become a mainstay of K-12 reform curricula (Radford, 2000; Noss, Healy \& Hoyles, 1997).

Contrast this with the modeling activity of the structural engineer. The lack of accessible physical referents and real data can place the engineer in a context of considerable uncertainty. Characterizing structural behavior forces her to cobble together strategies that draw on a variety of skills, knowledge, and resources, including past experience with materials ${ }^{10}$, theories about standard elements, and general empirical information in codebooks and manuals. In the process, she must justify any conclusions about the phenomenon before incorporating them into an analytic model. None of the major challenges — the uncertainty, the requirement to tell a story 
based on knowledge of a phenomenon that precedes the mathematical description, the need to integrate diverse resources and cognitive tools, the use of analogies, and the struggle to justify what can never really be proven—is likely to be experienced by a student working out a generalization exercise. One obvious similarity turns out to be superficial: engineers, like students engaged in generalization tasks, use a variety of representation forms—graphs, words, equations, pictures, and tables—but rarely to express patterns discerned from data. The engineer must adhere to the rules of the industry, which include established theoretical patterns and relationships among variables; she is not expected to invent her own.

Engineering and scholastic modeling tasks diverge in other ways. Engineers must navigate the reciprocal relationship between model and reality. Engineering models not only reflect phenomena, they determine them, an inevitable condition of any work that involves designing new phenomena into existence. Modeling for engineers is a combined act of describing and inventing stories about structural behavior. K-12 modeling tasks omit this twoway causality between model and reality. Because students model only existing phenomena, they have no opportunity to understand models as anything but descriptive.

Engineering modeling is by necessity context-dependent and context-specific. Mathematics of course plays an essential role —as the language of the theories that ground models and analyses, as a tool for evaluating analytic results, and as a means of representation and communication. But mathematical theories, methods, and representations cannot determine design or completely direct analysis. They are always subordinate to the engineer's judgment about their use, and mathematical justification alone is insufficient for accepting a model or method or result. The engineer's knowledge of the specifics of the structural situation influences virtually every stage of the modeling process; thus the model that ultimately emerges is deeply 
rooted in the situation. To import that model to a new situation would require the engineer to negotiate with the new contextual specifics to judge the appropriateness of the model and make necessary adaptations. In contrast, the models used or derived in the classroom can usually be decontextualized or abstracted away from the real situation to become pure mathematical entities, whose appropriateness can be justified with mathematical proof. Once a pattern is detected in the (readily available) data, the real phenomenon reflected by the data becomes irrelevant, disposable; the task becomes only to write a function or draw a graph to represent the mathematical pattern. The NCTM (2000) offers this example:

If a sandwich costs $\$ 3$, you can figure out how many dollars any number of sandwiches costs.... In this case, students have developed a model of a proportional relationship: the value of one variable (total cost, $C$ ) is always three times the value of the other (number of sandwiches, $S$ ) or $C=3 \cdot S$. (p. 162)

Once enough sample data are generated (e.g., $(1,3)(2,6),(3,9))$, the pattern can be discovered and the formula derived with no further reference to sandwiches or the considerations of pricing. And, unlike in engineering, the same formula would automatically be considered a fitting model for any other situation that generated the same data. This example departs further from most real problems in that no information is lost in translation from situation to model. Rarely in real problems is a single, objectively correct pattern or relationship hiding in the data, waiting to be discovered; even if a "correct" mathematical model existed, it would almost never be an equation exactly defined by the data pairs. Bissell and Dillon (2000) presented a related criticism of engineering education: its focus on formal mathematical procedures "can obscure those very areas which mathematics is supposed to illuminate” (p. 6). Then 
Attention is diverted away from the physical behavior of the system and concentrated on the details of the mathematics. Mathematics then becomes a goal in itself and it is easy to forget or ignore the often quite fragile links that were originally set up between the system and its mathematical model. As a result, there can easily be confusion between those results and procedures which relate primarily to the mathematical structure of the model and those which may be interpreted (with care) in terms of the behavior of the system. (p. 6)

Confusion and forgetting the "fragile links" with reality can plague practicing engineers as well as students, but usually for engineers the cause is the complexity of their models. Engineering problems can simultaneously involve multiple levels and kinds of models, which may be distributed for storage across various locations, physical and conceptual. Some models are internally inconsistent, and some have unclear or fickle relationships with reality, which can compromise the value of practical knowledge for guiding work. These conditions all contribute to the challenge of keeping track of models during the course of developing, using, and justifying them. Little of this challenge is experienced by K-12 students, however, as the models ordinarily invoked in classroom tasks are simple, consistent, coherent, and testable.

None of this is meant to imply that the modeling exercises in reform curricula are devoid of pedagogical value. But their disparity from the modeling activity of engineers is likely to diminish their potential to yield the benefits expected by reformers, especially ones related to preparation for real-world problem solving. Tasks that more closely simulate the modeling of structural engineers-that involve work with inaccessible data, require both description and design of nonexistent phenomena, and elicit complex, fragmented, and inconsistent modelswould offer more than just sites for the clean application of mathematical techniques. They 
would enhance students' understanding of the target phenomena or situations as well as the mathematics concepts used to model them. They would push students' reasoning and justifying to higher levels and compel students to weave nonmathematical ideas and resources into that reasoning. And they would give students a more accurate-not to mention inviting-image of what adults do in high-tech workplaces, especially the kinds of problems they solve and how they use math.

The findings of this study, however, also suggest that importing or adapting adult modeling experiences to the classroom may be more complicated than reformers assume. Clearly, the educational benefits achieved hinge on the particulars of task design and implementation, but the actual relationship between features of classroom modeling tasks and learning outcomes is under-researched. Lesh and his colleagues (e.g., Lesh \& Kelly, 2000; Zawojewski, Chamberlin, Hjalmarson, \& Lewis, in press) offer a vision of how to conduct such research. Through multi-tier design experiments (Lesh \& Yoon, 2004), they collaborated with engineering educators to design authentic model-eliciting activities (MEAs) ${ }^{11}$ for middle-school students, while simultaneously investigating the learning of students engaged in the activities and revising the activities, in iterative cycles. The MEAs that emerged from this process present many more features of engineering modeling than the typical generalization exercise. In one MEA (Lesh \& Doerr, 2003), students devise a system for rating volleyball players during tryouts and formulating well-matched teams, based on individual statistics (e.g., vertical jump, spiking record, and speed). This is essentially a design task—no teams yet exist for the student to describe_-and the models elicited are likely to be complex, not one simple formula. And developing a "good” model depends not only on recognizing mathematical patterns in the data but also on understanding athletic skill, team dynamics, and the game of volleyball. 
The more authentically classroom tasks replicate the actual modeling activity of adults, the more time and resources they will probably need. Interdisciplinary teaching would be one way to meet this challenge: a project to mathematically model a physical phenomenon might require both a mathematics and science teacher to contribute class time, materials, and expertise. A further challenge is revealed by this study: the modeling expertise of engineers is at least as much a function of their knowledge of structures and industry conventions as of their knowledge of mathematics. In any field, much of an adult's modeling competence comes from years of experience in the occupational domain. Teachers and curriculum developers, therefore, must be careful to choose problem situations familiar to students, for which they have a basis for developing and judging the appropriateness of their models. Ranking tasks, like the volleyball problem, could ask students to develop systems for rating familiar phenomena: the "best" local restaurant, the "safest" car, or the "winning" country in the next Olympics (English \& Watters, 2005). More sophisticated ranking problems would rate items on the basis of qualitative, subjective features, such as "flavor" or "sportsmanship.” A different kind of modeling exercise that simulates some features of engineering modeling is to quantify complicated objects that are impossible to measure accurately, such as the surface area of a local pond or the volume of a human body. In other examples, students develop algorithms for system design, such as the most efficient routine for elevators (National Research Council, 1998). Integrating modeling projects with other subject-area classes can help students attain the required phenomenological understanding.

Sadly, the current political climate in the United States appears to be driving school mathematics programs away from the reforms of the 80s and 90s. Long lists of state- and district-mandated content topics and the high-stakes accountability measures that enforce their 
coverage naturally tilt the system towards curricula and methods that promise enhanced performance on external exams, which stress procedural proficiency. Constructivist, processoriented curricula—the ones likeliest to include modeling tasks—are expected to slow content coverage and thus incur punishments for teachers and students. The results of this study illustrate the danger of this trend. Where preparation for real-world problem solving is the goal, a return to traditional curricula and pedagogy appears to be a backwards move. Indeed, in the area of mathematical modeling, reform curricula have probably not yet stepped forward boldly enough. 


\section{References}

Bissell, C. \& Dillon, C. (2000). Telling tales: Models, stories, and meanings. For the Learning of Mathematics, 20(3), 3-11.

Boaler, J. (1999). Participation, knowledge, and beliefs: A community perspective on mathematics learning. Educational Studies in Mathematics, 40(3), 259-281.

Boaler, J. (2002). Learning from teaching: Exploring the relationship between reform curriculum and equity. Journal for Research in Mathematics Education, 33(4), 239-258.

Bucciarelli, L. L. (1994). Designing engineers. Cambridge: MIT Press.

Carpenter, T. P. \& Rhomberg, T. A. (2004). Powerful practices in mathematics and science. Madison, WI: National Center for Improving Student Learning and Achievement in Mathematics and Science.

Carraher, D. W. \& Schliemann, A. D. (2002). Is everyday mathematics truly relevant to mathematics education? In M. E. Brenner \& J. N. Moschkovich (Eds.), Everyday and academic mathematics in the classroom (pp. 131-153). Reston, VA: National Council of Teachers of Mathematics.

Cognition \& Technology Group at Vanderbilt, 1990. Anchored instruction and its relationship to situated cognition. Educational Researcher, 19(6), 2-10.

Crandall, S. H. (1956). Engineering analysis: A survey of numerical procedures. New York: McGraw-Hill.

DaPueto, C. \& Parenti, L. (1999). Contributions and obstacles of contexts in the development of mathematical knowledge. Educational Studies in Mathematics, 39, 1-21.

De la Rocha, O. (1985). The reorganization of arithmetic practice in the kitchen. Anthropology and Education Quarterly, 16(3), 193-198. 
Doerr, H. M. \& English, L. D. (2003). A modeling perspective on students’ mathematical reasoning about data. Journal for Research in Mathematics Education, 34(2), 110-136.

Edwards, D. \& Hamson, M. (1989). Guide to mathematical modelling. Boca Raton, FL: CRC Press.

English, L. D., \& Watters, J. J. (2005). Mathematical modelling with nine-year-olds. Proceedings of the $29^{\text {th }}$ Annual Conference of the International Group for the Psychology of Mathematics Education. Melbourne.

Forman, S. L. \& Steen, L.A. (1995). Mathematics for work and life. In I. M. Carl (Ed.), Prospects for school mathematics (pp. 219-241). Reston, VA: National Council of Teachers of Mathematics.

Gravemeijer, K. (2004). Emergent modeling as a precursor to mathematical modeling. In H-W. Henn \& W. Blum (Eds.), ICMI Study 14: Applications and modelling in mathematics education, pre-conference volume. Dortmund: Universität Dortmund, pp. 97-102.

Gravemeijer, K. \& Doorman, M. (1999). Context problems in realistic mathematics education: A calculus course as an example. Educational Studies in Mathematics, 39, 111-129.

Greeno, J. G. \& MMAP. (1997). Theories of practices of thinking and learning to think. American Journal of Education, 106(1), 85-126.

Henderson, K. (1999). On line and on paper: Visual representations, visual culture, and computer graphics in deign engineering. Cambridge, MA: The MIT Press.

Kent, P. and Noss, R. (2002). The mathematical components of engineering expertise: The relationship between doing and understanding mathematics. Paper submitted to the Institution of Electrical Engineers Annual Symposium on Engineering Education, London, January, 2002. 
Lave, J. (1988). Cognition in practice: Mind, mathematics, and culture in everyday life. New York: Cambridge University Press.

Lehrer, R. \& Schauble, L. (2003). Origins and evolution of model-based reasoning in mathematics and science. In R. Lesh \& H. M. Doerr (Eds.), Beyond constructivism: Models and modeling perspectives on mathematics problem solving, learning, and teaching (pp. 59-70). Mahwah, NJ: Lawrence Erlbaum Associates.

Lehrer, R., Schauble, L., Strom, D., \& Pligge, M. (2001). Similarity of form and substance: From inscriptions to models. In D. Klahr \& S. Carver (Eds.), Cognition and instruction: 25 years of progress (pp. 39-74). Mahwah, NJ: Lawrence Erlbaum Associates.

Lesh, R., Cramer, K., Doerr, H. M., Post, T., \& Zawojewski, J. S. (2003). Model development sequences. In R. Lesh \& H. M. Doerr (Eds.), Beyond constructivism: Models and modeling perspectives on mathematics problem solving, learning, and teaching (pp. 3558). Mahwah, NJ: Lawrence Erlbaum Associates.

Lesh, R., \& Doerr, H. M. (2003). Foundations of a models and modeling perspective on mathematics teaching, learning, and problem solving. In R. Lesh \& H. M. Doerr (Eds.), Beyond constructivism: Models and modeling perspectives on mathematics problem solving, learning, and teaching (pp. 3-33). Mahwah, NJ: Lawrence Erlbaum Associates.

Lesh, R. \& Kelly, E. (2000). Multi-tiered teaching experiments. In E. Kelly \& R. Lesh (Eds.), Handbook of research design in mathematics and science education. Mahwah, NJ: Lawrence Erlbaum Associates.

Lesh, R., Lester, F. K., Jr., \& Hjalmarson, M. (2003). A models and modeling perspective on metacognitive functioning in everyday situations where problem solvers develop mathematical constructs. In R. Lesh \& H. M. Doerr (Eds.), Beyond constructivism: 
Models and modeling perspectives on mathematics problem solving, learning, and teaching (pp. 383-403). Mahwah, NJ: Lawrence Erlbaum Associates.

Lesh, R. \& Yoon, C. (2004). What is distinctive in (our views about) models and modeling perspectives on mathematics problems solving, learning, and teaching? In H-W. Henn \& W. Blum (Eds.), ICMI Study 14: Applications and modelling in mathematics education, pre-conference volume. Dortmund: Universität Dortmund.

Mathematical Association of America. (2000). Proceedings of the Curriculum Foundations Workshop in Engineering. Clemson University.

McClain, K. (2003). Task-analysis cycles as tools for supporting students’ mathematical development. In R. Lesh \& H. M. Doerr (Eds.), Beyond constructivism: Models and modeling perspectives on mathematics problem solving, learning, and teaching (pp. 175189). Mahwah, NJ: Lawrence Erlbaum Associates.

Middleton, J. A., Lesh, R., \& Heger, M. (2003). Interest, identity, and social functioning: Central features of modeling activity. In R. Lesh \& H. M. Doerr (Eds.), Beyond constructivism: Models and modeling perspectives on mathematics problem solving, learning, and teaching (pp. 405-431). Mahwah, NJ: Lawrence Erlbaum Associates.

National Council of Teachers of Mathematics (NCTM). (2000). Principles and standards for school mathematics. Reston, VA: NCTM.

National Research Council. (1998). High school mathematics at work: Essays and examples for the education of all students. Washington, DC: National Academy Press.

Nersessian, N. J. (1992). How do scientists think? Capturing the dynamics of conceptual change in science. In R. N. Giere (Ed.), Cognitive models of science (pp. 3-45). Minneapolis: University of Minneapolis Press. 
Noss, R., Healy, L., \& Hoyles, C. (1997). The construction of mathematical meanings: connecting the visual with the symbolic. Educational Studies in Mathematics, 33(2), 203233.

Nunes, T., Schliemann, A. D., \& Carraher, D. W. (1993). Street mathematics and school mathematics. New York: Cambridge University Press.

Perlow, L. \& Bailyn, L. (1997). The senseless submergence of difference: Engineers, their work, and their careers. In S. R. Barley \& J. E. Orr, (Eds.), Between craft and science: Technical work in U.S. settings (pp. 230-243). Ithaca, NY: ILR Press.

Radford, L. (2000). Signs and meanings in students' emergent algebraic thinking: A semiotic analysis. Educational Studies in Mathematics, 42(3), 237-268.

Roth, W. -M., McGinn, M. K., \& Bowen, G. M. (1998). How prepared are preservice teachers to teach scientific inquiry? Levels of performance in scientific representation practices. Journal of Science Teacher Education, 9(1), 25-48.

Scribner, S. (1984). Studying working intelligence. In B. Rogoff \& J. Lave (Eds.), Everyday cognition: Its development in social context (pp. 9-40). Cambridge: Harvard University Press.

Smith, E., Haarer, S., \& Confrey, J. (1993). Seeking diversity in mathematics education: Mathematical modeling in the practice of biologists and mathematicians. Paper presented at the Annual Meeting of the American Educational Research Association, Atlanta, GA, April 12-16, 1993.

Smith, J. P. (1999). Tracking the mathematics of automobile production: Are schools failing to prepare students for work? American Educational Research Journal, 36(4), 835-878. 
Society for Industrial and Applied Mathematics (SIAM). (1998). Report on mathematics in industry. Philadelphia: SIAM.

Stevens, R. (1999). Disciplined perception: Comparing the development of embodied mathematical practices at work and school. (Doctoral dissertation, University of California, Berkeley, 1999). Dissertation Abstracts International, A60/06.

Stevens, R. \& Hall, R. (1998). Disciplined perception: Learning to see in technoscience. In M. Lampert \& M. L. Blunk (Eds.), Talking mathematics in school: Studies of teaching and learning (pp. 107-149). Cambridge: Cambridge University Press.

Tate, W. F., IV. (2001). Mathematizing and the democracy: The need for an education that is multicultural and social reconstructionist. In C. A. Grant and M. L. Gomez (Eds.), Campus and classroom: Making schooling multicultural. Upper Saddle River, NJ: Prentice Hall.

Vincenti, W. G. (1990). What engineers know and how they know it: Analytical studies from aeronautical history. Baltimore: The Johns Hopkins University Press.

Zawojewski, J., Chamberlin, M., Hjalmarson, M., \& Lewis, C. (in press). The role of design studies in teacher professional development. In E. Kelly \& R. Lesh (Eds.), Design research in mathematics, science and technology education. Mahwah, NJ: Lawrence Erlbaum Associates. 


\section{Footnotes}

${ }^{1}$ But see Boaler (2002) for a discussion of the importance of specific teacher practices to mitigate the potentially reduced effectiveness of contextualized curricula for students of lower socioeconomic classes or minority cultures.

${ }^{2}$ Structural engineers will conceptualize a variety of elements and structures as beams. For some analytic purposes, engineers will even treat a tall, narrow building, as a single beam.

${ }^{3}$ All names used in this article for engineers and their firms are pseudonyms.

${ }^{4}$ Actually, not evenly but in direct proportion to the stiffness of each wall. The important feature of this assumption, however, is that the location of the lower story wall on the floor is irrelevant to the amount of compression force transmitted to it from the upper story wall.

${ }^{5}$ All dialogue presented in this article was transcribed verbatim from audiotape.

${ }^{6}$ This envelope strategy recalls a form of everyday quantitative problem solving observed by Lave (1988) that she termed gap-closing.

${ }^{7}$ Outside the firms, I encountered metaphorical terms for models in general. In a structures course I audited, the professor referred to particular, established graphs as “cartoons” because they oversimplified the relationships they depicted. The mathematical biologist studied by Smith, Haarer, and Confrey (1993) called a certain model a “caricature.” Bissell and Dillon, in their quote, refer to models of behavior as "stories.” Similarly, Bucciarelli chose the metaphor “story making” to describe how engineers created accounts of design objects. Even at this general level, these metaphorical terms seem intended to facilitate keeping track, in that they distinguish models from reality and remind their audiences not to mistake the representation for the actual phenomenon. 
${ }^{8}$ Torsion refers to the in-plane rotation of the floor around its center of rigidity, the theoretical center of the lateral resistance provided by the walls. The external lateral load is presumed to hit at the floor's center of mass, or centroid. When the centroid and the center of rigidity are unaligned (the usual situation), torsion results. Torsion imposes extra force on the walls, on top of the force directly imposed by the external load.

${ }^{9}$ Chord members form the beam’s upper and lower edges and resist compression and tension when the beam bends. Eric is indicating that wood reinforcement along the edges of the floor will act as the chords of his theoretical beam.

${ }^{10}$ Because all of my observations occurred in their offices, I did not see the engineers directly engaged with physical elements and I initially underestimated the role of experiential knowledge about structures. Later interviews, however, revealed that for many engineers personal experience with elements and lab-test photos are powerful resources for keeping modeling activity on track.

${ }^{11}$ Lesh and Doerr (2003) define model-eliciting activities as problem-solving activities in which students produce "sharable, manipulatable, modifiable, and reusable conceptual tools (e.g., models) for constructing, describing, explaining, manipulating, predicting, or controlling mathematically significant systems” (p. 3). 


\section{Figure Captions}

Figure 1. Rigid-floor behavior: The compression force $\left(V_{2}\right)$ on $2^{\text {nd }}$-story Wall $A_{2}$ is transmitted evenly through the floor to the three $1^{\text {st }}$-story Walls $\mathrm{A}_{1}, \mathrm{~B}_{1}$, and $\mathrm{C}_{1}$, imposing a force of (1/3) $V_{2}$ on each. ( $V$ conventionally represents a lateral force.) (In the flexible-floor model, all of $V_{2}$ would travel directly down into Wall $A_{1}$; Walls $B_{1}$, and $C_{1}$ would receive none of this force.) Figure 2. Tim's sketch (redrawn) of the 4-story core and the 3-story areas of the Spring Valley Apartments.

Figure 3. Two tiedowns on a 4-story wall.

Figure 4. Three tiedowns on a 4-story wall.

Figure 5. The rigid-floor model might report too little force being transmitted from the core to Wall A and too much to Wall B.

Figure 6. Eric's sketch (redrawn) modeling the floor as a "beam.” The dark lines indicate the boundaries, or chords, of the beam, with approximate dimensions $100^{\prime} \mathrm{x} 38^{\prime} . \mathrm{V}$ represents the shear force, the triangles represent the "supports" (and therefore the demand) on each end of the beam, and the large " $\mathrm{X}$ ” represents a courtyard hole. 
Modeling of Engineers 53

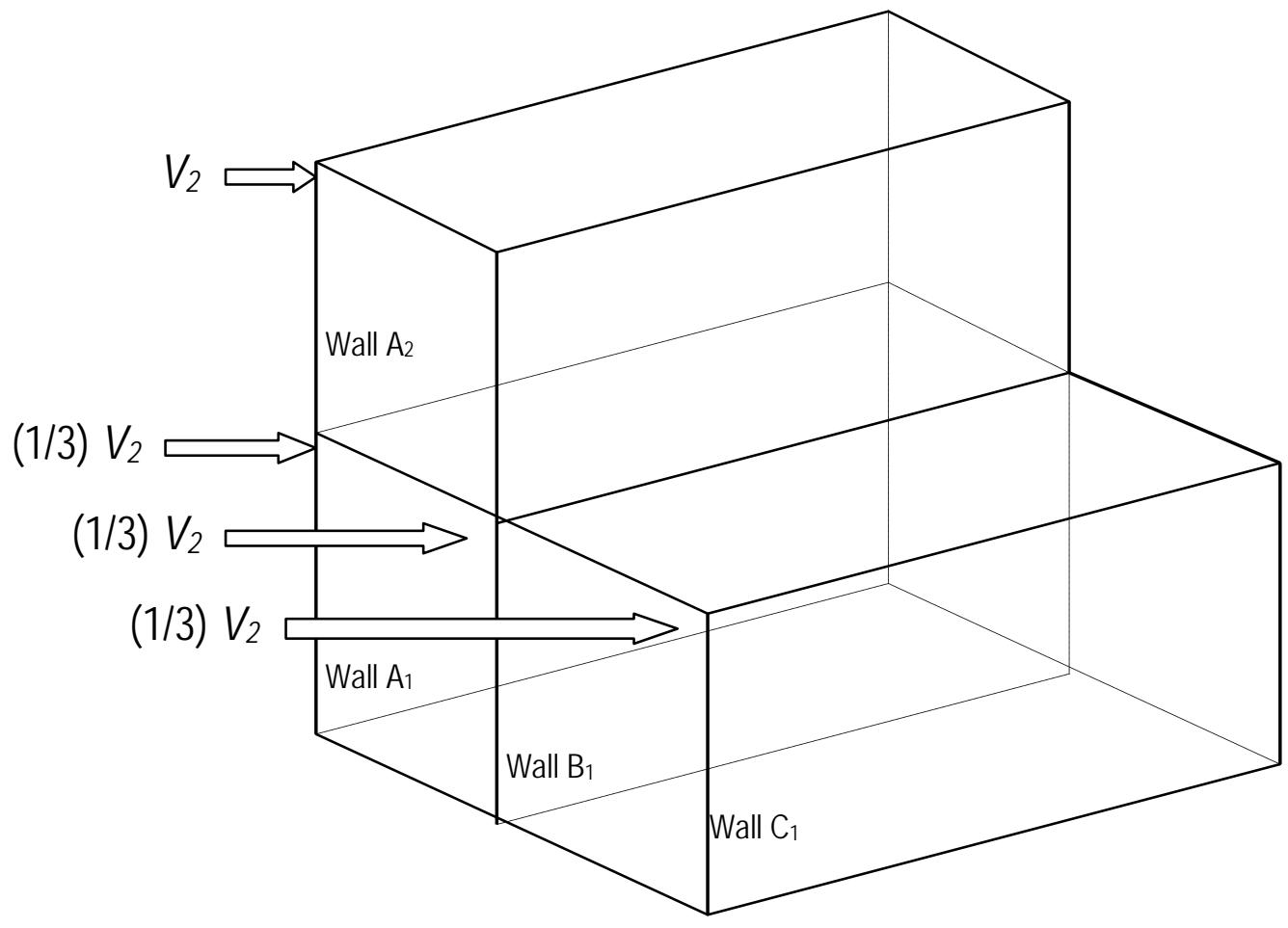


Modeling of Engineers 54

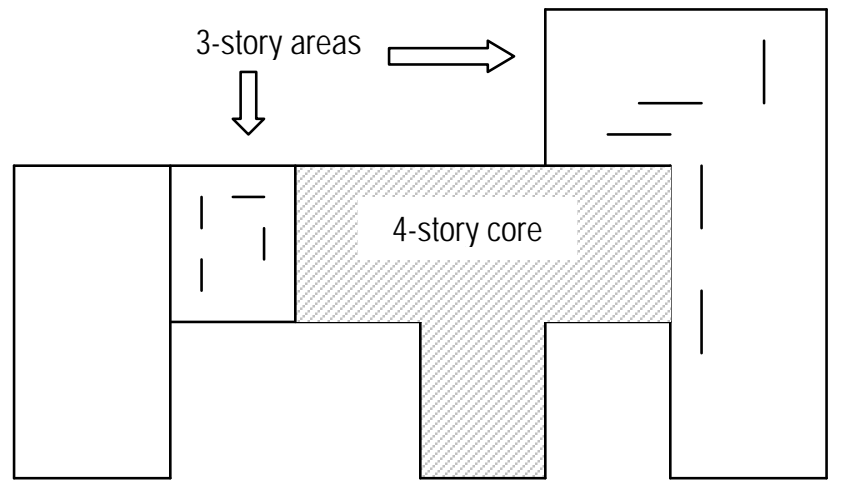




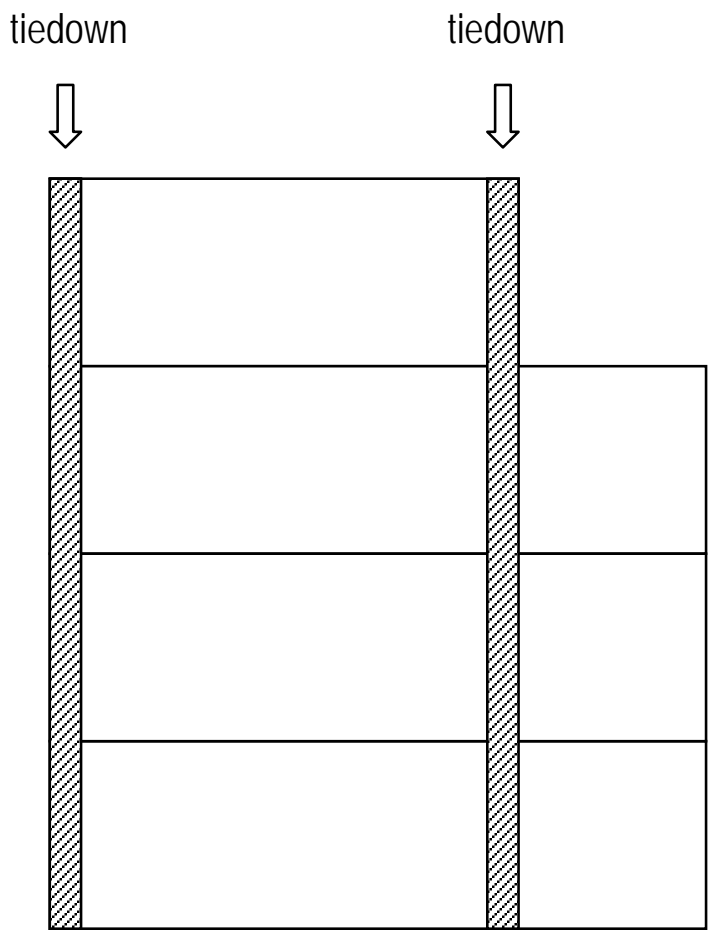




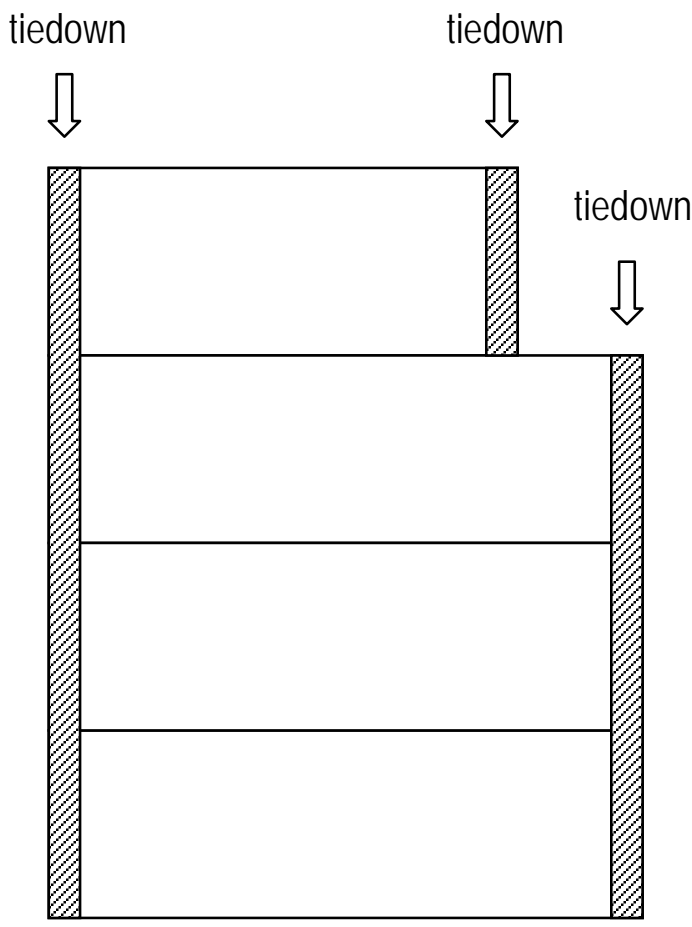


Modeling of Engineers 57

3-story area

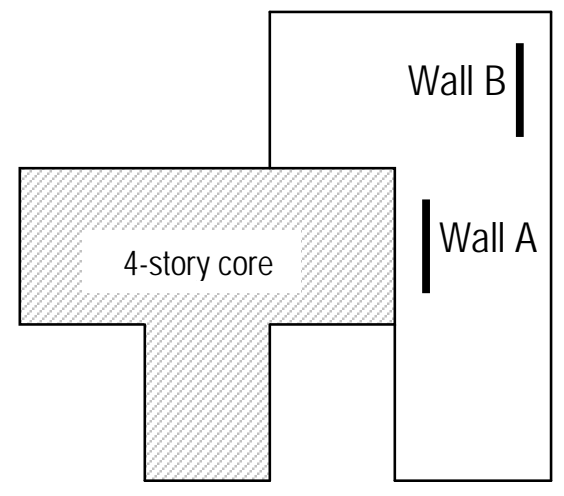


Modeling of Engineers 58

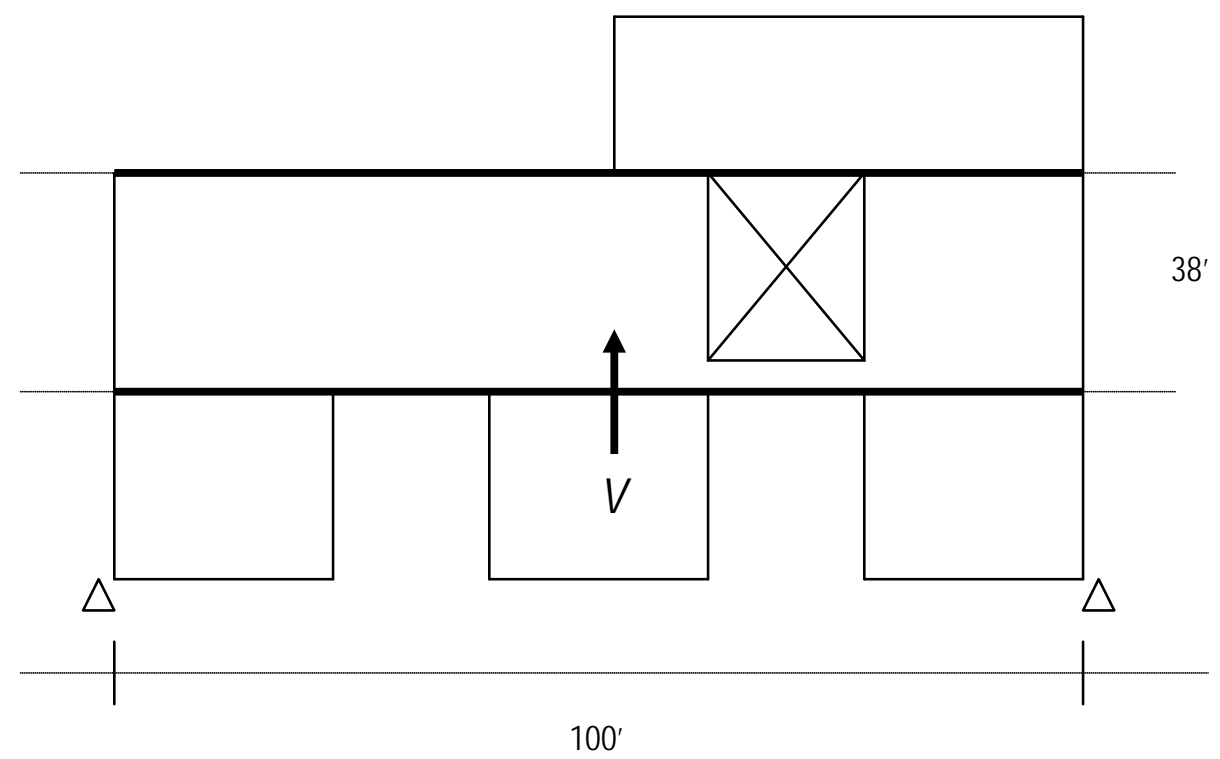

